\title{
Perancangan Aplikasi Modul Pembelajaran Membaca Cepat Dengan Metode Satu Bulan Bisa Baca Berbasis Web Mobile (Studi Kasus TK Ibnu Sina Batam)
}

\author{
Okta Veza*1, Hanafi ${ }^{2}$, Yusniah ${ }^{3}$ \\ ${ }^{1,2,3}$ STT Ibnu Sina; Jl.Teuku Umar - Lubuk Baja; telp/fax : 0778-425391/ 0778-458394 \\ ${ }^{1,2,3}$ Program Studi Teknik Informatika, STT Ibnu Sina, Batam \\ e-mail: ${ }^{* 1}$ Okta@stt-ibnusina.ac.id, ${ }^{2}$ hanafi@ @stt-ibnusina.ac.id
}

\begin{abstract}
Abstrak
Taman Kanak-kanak adalah jenjang pendidikan dasar yang merupakan suatu upaya pembinaan yang ditujukan untuk anak sejak lahir sampai dengan usia enam tahun yang dilakukan melalui pemberian rangsangan pendidikan untuk membantu pertumbuhan dan perkembangan jasmani dan rohani anak agar memiliki kesiapan dalam memasuki pendidikan yang lebih lanjut. Pada penelitian ini akan dirancang sebuah aplikasi pembelajaran dengan mengaplikasikan modul pembelajaran membaca cepat dengan Metode Satu Bulan Bisa Baca ke dalam web mobile. Dalam perancangan aplikasi ini, diperlukan suatu observasi untuk mengetahui materi-materi yang diberikan dan minat para siswa agar dalam perancangan aplikasi nanti bisa sesuai dengan apa yang diminati oleh para siswa. Aplikasi pembelajaran ini berfungsi sebagai alat yang membantu siswa dalam belajar membaca cepat di TK Ibnu Sina Batam.
\end{abstract}

Kata kunci: Aplikasi, Modul Pembelajaran, Web Mobile.

\begin{abstract}
Kindergarten is the level of basic education which is a coaching effort aimed at children from birth up to the age of six years is done through the provision of educational stimulus to help the growth and development of physical and spiritual children to have readiness in entering further education. In this research will be designed a learning application by applying the fast reading learning module with One Month Method Can Read into the mobile web. In designing this application, it is necessary an observation to know the given materials and interests of the students so that in the design of the application can be in accordance with what is interested by the students. This learning application serves as a tool that helps students in learning to read fast in kindergarten Ibnu Sina Batam.
\end{abstract}

Key Word: Application, Learning Module, Web Mobile

\section{PENDAHULUAN}

Berdasarkan Kurikulum Tingkat Satuan PAUD (KTSP) TK Ibnu Sina Batam Pendidikan Anak Usia Dini merupakan pendidikan yang paling fundamental karena pertumbuhan dan perkembangan anak dimasa selanjutnya akan sangat ditentukan oleh berbagai stimulasi bermakna yang diberikan sejak usia dini dan diyakini menjadi dasar bagi penyiapan sumber daya manusia yang berkualitas dimasa yang akan datang.

Kurikulum menurut Undang-undang No.23 tahun 2002 tentang perlindungan anak pasal 9 ayat 1 menyebutkan:" setiap anak berhak memperoleh pendidikan dan pengajaran dalam rangka pengembangan pribadinya dan tingkat kecerdaannya sesuai minat dan bakatnya”, Undang-undang 
Nomor 20 tahun 2003 tentang Sistem Pendidikan Nasional, Bab I Pasal 1 poin 19 adalah seperangkat rencana dan pengaturan mengenai tujuan, isi, dan bahan pelajaran serta cara yang digunakan sebagai pedoman penyelenggaraan kegiatan pembelajaran untuk mencapai tujuan pendidikan tertentu.

Anak Usia Dini umumnya sudah mampu berkomunikasi secara lisan, namun untuk membaca anak masih mengalami kesulitan mengingat bahasa yang rumit dan melibatkan berbagai unsure seperti huruf, kata, kalimat dan tata cara melafalkannya. Untuk mengembangkan kemampuan membaca pada anak, guru harus mampu menciptakan suatu pembelajaran yang mampu membuat anak termotivasi untuk belajar.

Metode SB3 (Satu Bulan Bisa Baca) adalah teknik belajar membaca kalimat bahasa Indonesia dengan menghapal dan merangkai suku kata dengan tanpa mengeja. Proses menghapal dan merangkai suku kata tersebut berlaku secara sistematis, yaitu rata-rata tiga suku kata perjam pelajaran setiap hari selama tiga puluh hari, dengan ketentuan suku kata dengan vokal (a) mulai hari kesatu sampai sepuluh, selanjutnya masing-masing selama lima hari secara berurutan, yaitu suku kata dengan vokal (i) dari hari kesupuluh sampai lima belas, vokal (u) lima belas sampai duapuluh, vokal (e) dua puluh sampai dua puluh lima dan vokal (o) dua puluh lima sampai hari ketiga puluh.

Oleh karena itu, dari beberapa hal yang telah dijelaskan maka penulis tertarik mengangkat permasalahan dalam penelitian dengan judul "Perancangan Aplikasi Modul Pembelajaran Membaca Cepat dengan Metode Satu Bulan Bisa Baca Berbasis Web Mobile (Studi Kasus TK Ibnu Sina Batam)".

\section{METODOLOGI PENELITIAN}

Tahapan dan ruang lingkup pekerjaan yang akan dilaksanakan pada penelitian ini dapat digambarkan seperti gambar di bawah ini

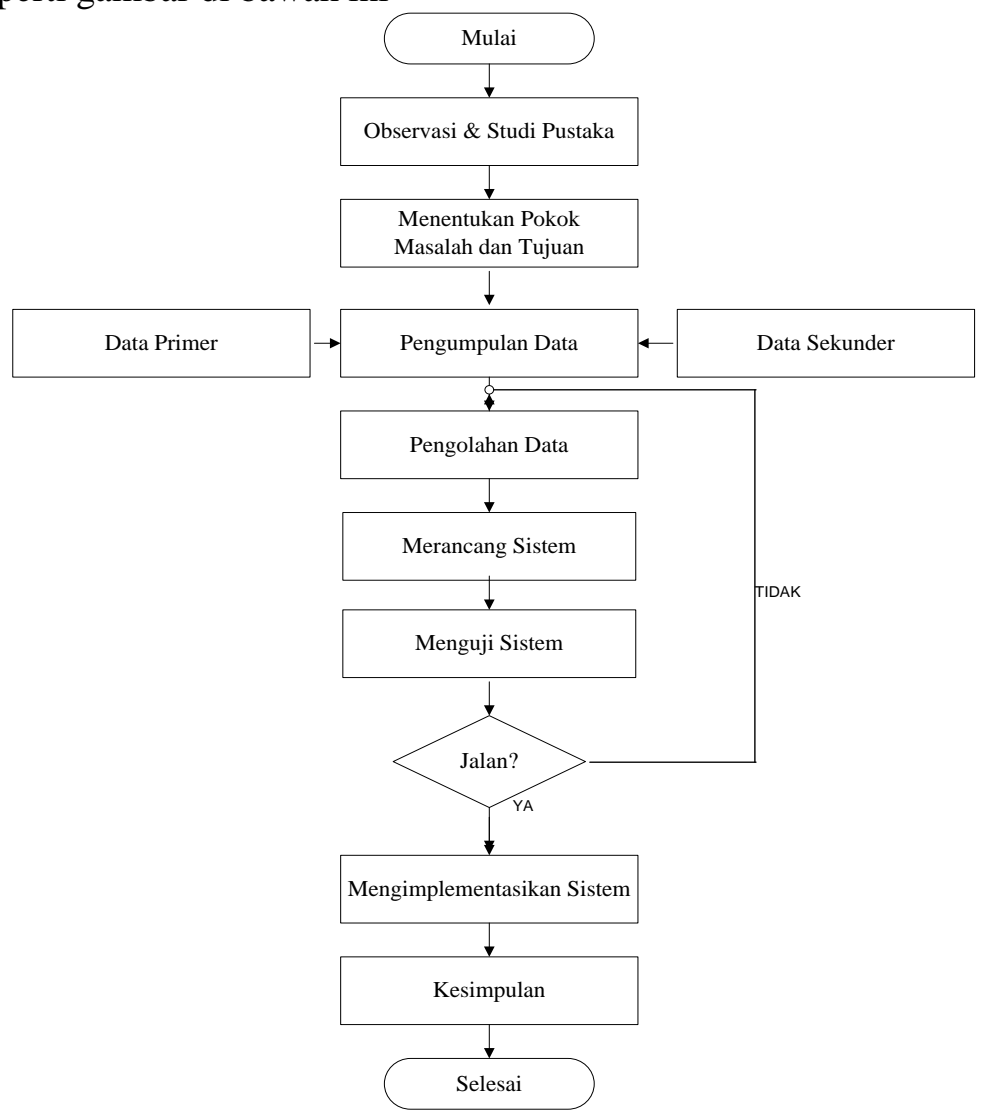

Gambar 1. Kerangka Pemecahan Masalah

Desember 2017 | Vol. 1 | No. 1 | ISSN : 2614-7602 


\section{PEMBAHASAN}

\subsection{Analisa Sistem}

Penelitian dan pengumpulan data pada sistem yang berjalan dengan tujuan mendapatkan data secara lengkap untuk dapat merancang sistem yang baru atau sistem yang akan diperbaharui dari sistem yang sedang berjalan

\section{Aliran Sistem Informasi yang Sedang Berjalan}

Pada Aliran Sistem Informasi yang sedang berjalan semua kegiatan yang berhubungan dengan sistem pembelajaran di TK Ibnu SinaBatam masih dilakukan secara manual, untuk lebih jelasnya silahkan memperhatikan gambar 2. aliran system informasi yang sedang berjalan di TK Ibnu Sina Batam dibawah ini :

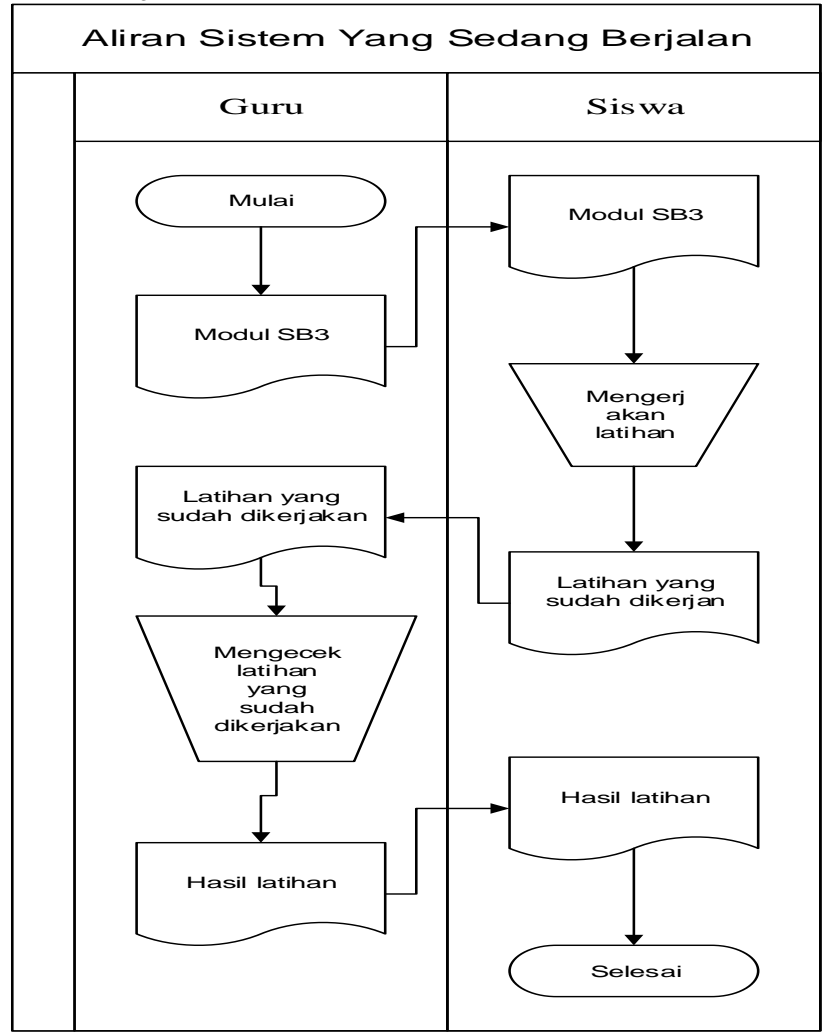

Gambar 2. Aliran SI yg Berjalan

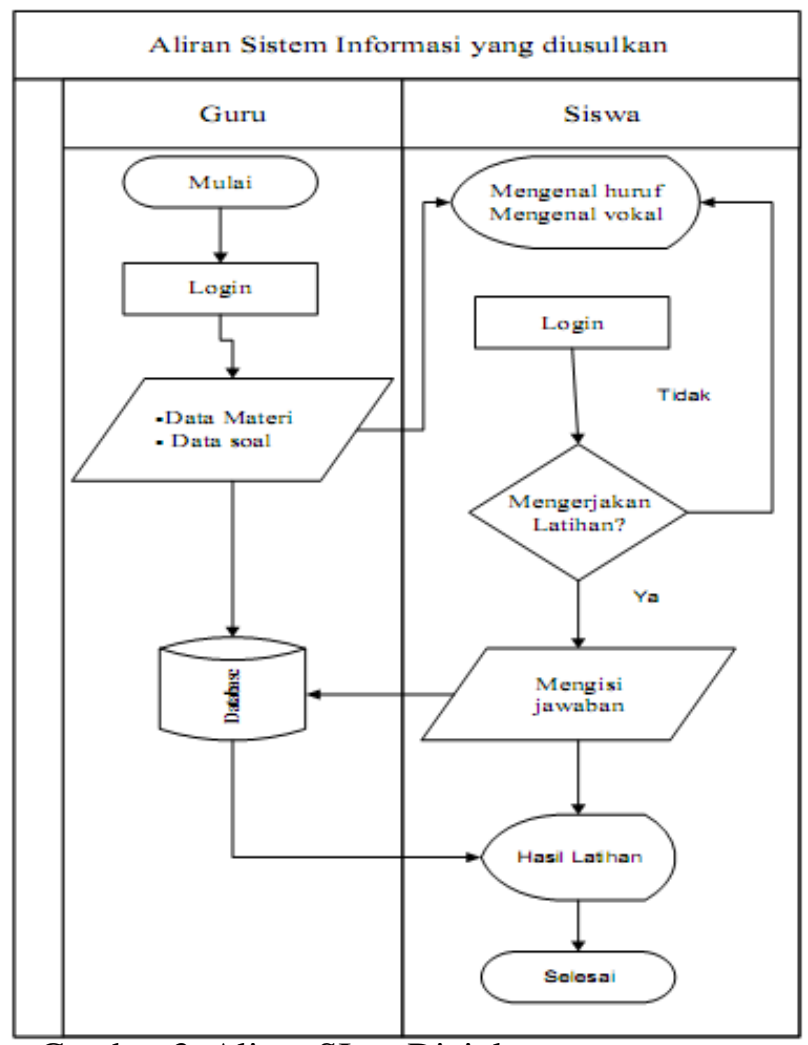

Gambar 3. Aliran SI yg Diajukan

\section{Aliran Sistem Informasi yang diusulkan}

Pada Aliran Sistem Informasi yang yang akan diusulkan disini akan tergambar dengan jelas cara kerja dari system yang akan dirancang yang sesuai dengan kebutuhan yang ada di TK Ibnu Sina Batam, untuk lebih jelasnya silahkan melihat gambar 3.2 dibawah ini :

\subsection{Data Flow Diagram (DFD)}

Pada tahap ini peneliti akan menunjukkan usulan alur proses sistem yang akan dibuat sesuai dengan aliran system yang akan diusulkan pada gambar 3.2 diatas. Untuk menunjukkan fungsi-fungsi sistem kepada user secara logika dengan menggunakan tools DFD (Data Flow Diagram) silahkan melihat gambar 3.2.1 dari diagram context dan 3.2.2 untuk Data Flow Diagram dibawah ini :

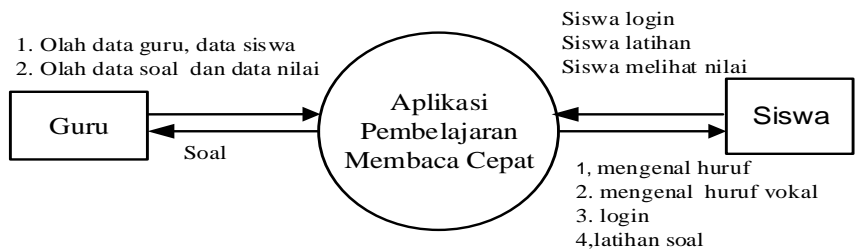

Gambar 4. Diagram Konteks. 


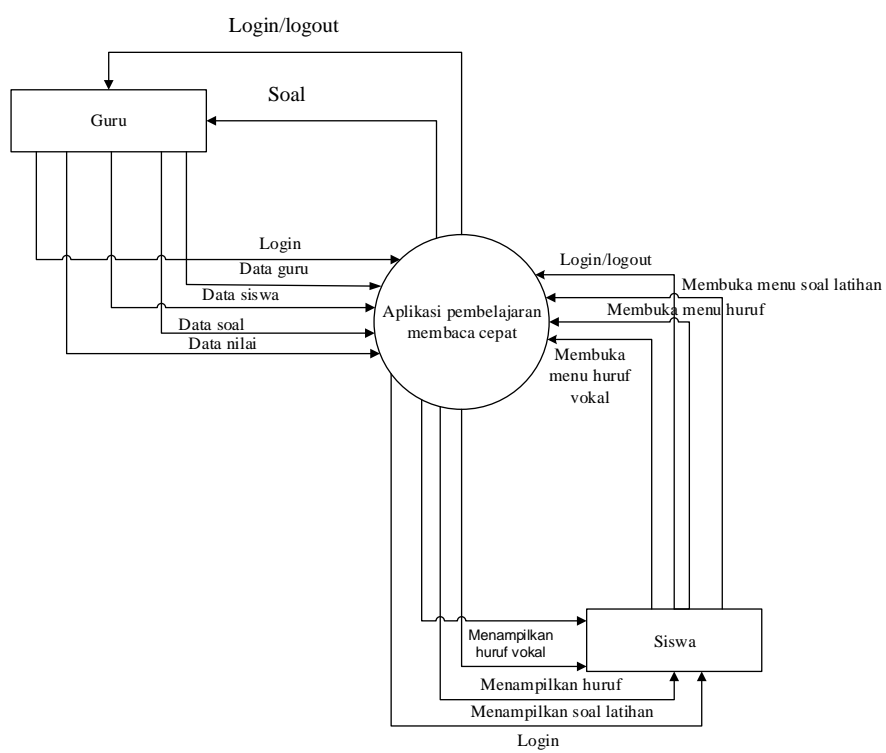

Gambar 5. Data Flow Diagram Level 0

\subsection{Entity - Relationship Diagram}

Relasi tabel dalah gambaran alur ketersambungan antar tabel satu dengan tabel yang lain yang biasa di sebut Entity-Relationship Diagrams (ERD), adapun gambarannya ERD dari aplikasi yang akan dirancang adalah sebagai berikut:

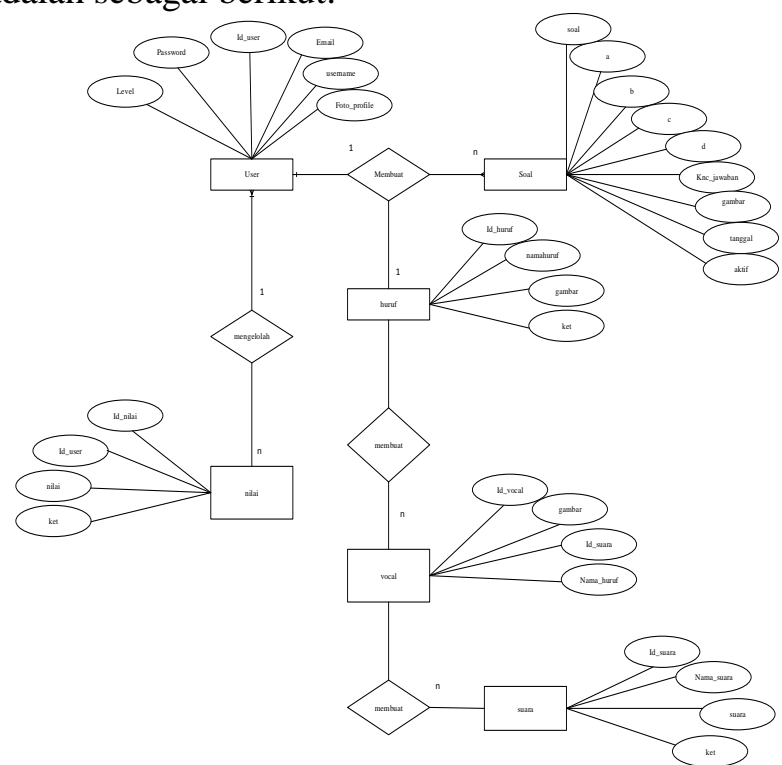

Gambar 6. Entity Relation Diagram (ERD).

\section{IMPLEMENTASI SISTEM}

\subsection{Penjelasan Program}

Didalam penjelasan program ini dijelaskan tentang alur pembuatan dan kegunaan program yang dibuat beserta tampilan disain. Berikut ini tampilan-tampilan halaman yang ada dalam program yang dibuat :

1. Halaman Utama, yaitu halaman awal saat membuka program maka akan tampil halaman awal pada Program pembelajaran membaca di TK Ibnu Sina Batam 


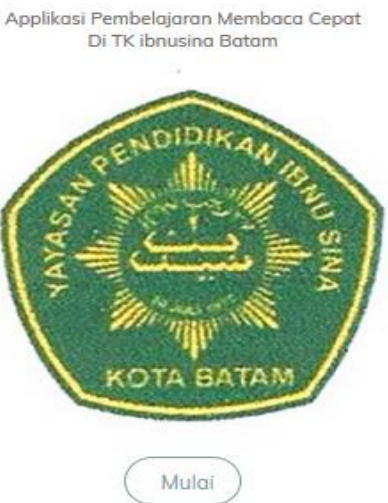

Gambar 7. Hal Utama

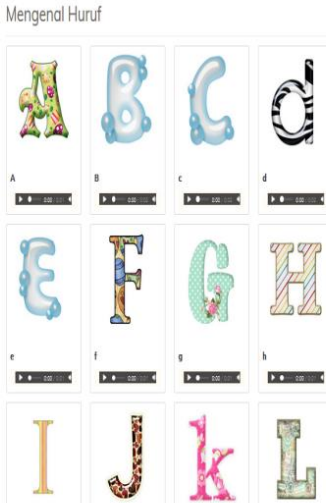

Gambar 8. Hal Mengenal Huruf

2. Pada halaman Tampilan Mengenal huruf saat huruf diklik maka akan timbul bunyi suara sesuai dengan huruf yang diklik :

3. Begitu juga pada tampilan halaman mengenal huruf vocal, hanya saja pada gambar di halaman mengenal huruf vocal, pada setiap gambar menggunakan gambar bergerak (gambar gift).

4. Halam an login pada aplikasi pembelajaran digunakan untuk masuk kedalam aplikasi sisterm pembelajaran membaca dengan cara sebagai berikut:

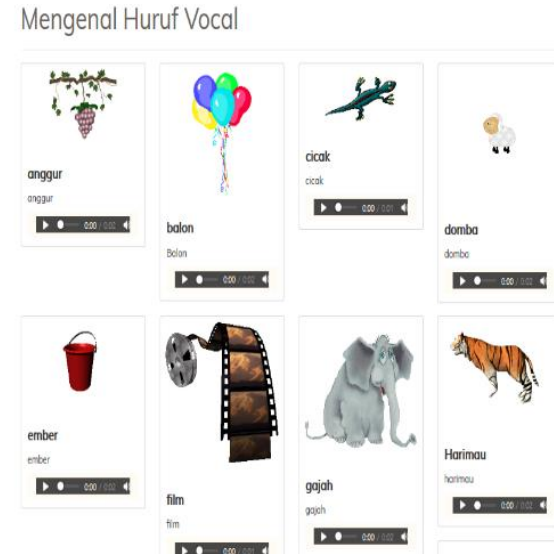

Gambar 9. Hal Mengenal Vocal

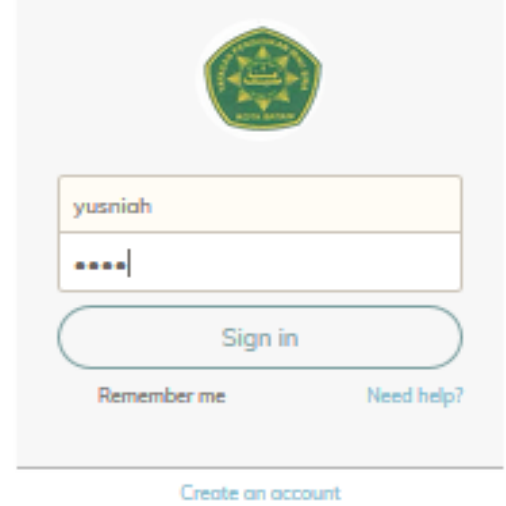

Gambar 10. Tampilan Login Langkah-langkah yang harus dilakukan pada halaman login adalah:

a) Memasukkan username yang tersedia.

b) Memasukkan password sebagai kata kunci untuk masuk ke halaman utama aplikasi.

c) Klik Sign

5. Pada tampilan data di bawah ini dapat dilihat tampilan data user dan suara yang diakses oleh guru secera full akses dari aplikasi yang dirancang :

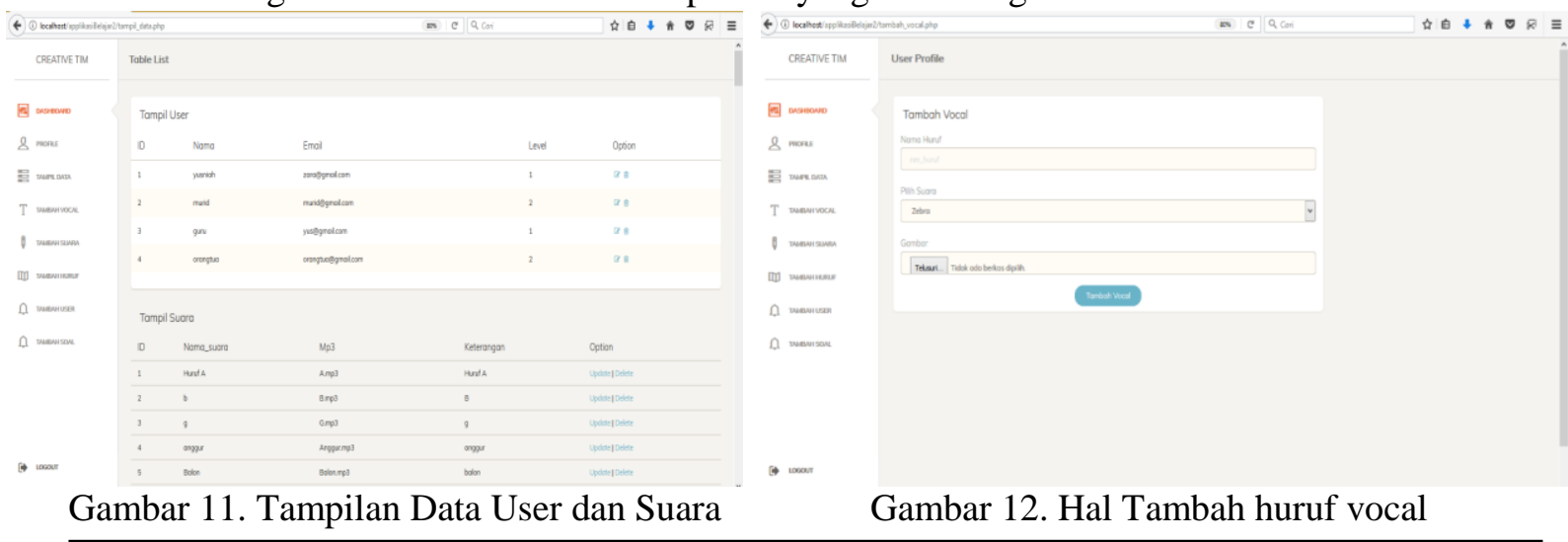

(JR) Jurnal Responsive Teknik Informatika, Sekolah Tinggi Teknik Ibnu sina - Batam 
6. Pada halaman tambah huruf vocal, guru atau user dapat menambah huruf sesuai yang diinginkan sama juga dengan hal nya menambah huruf, menambah suara, dan menambah soal. tampilannya dapat dilihat pada gambar dibawah ini :

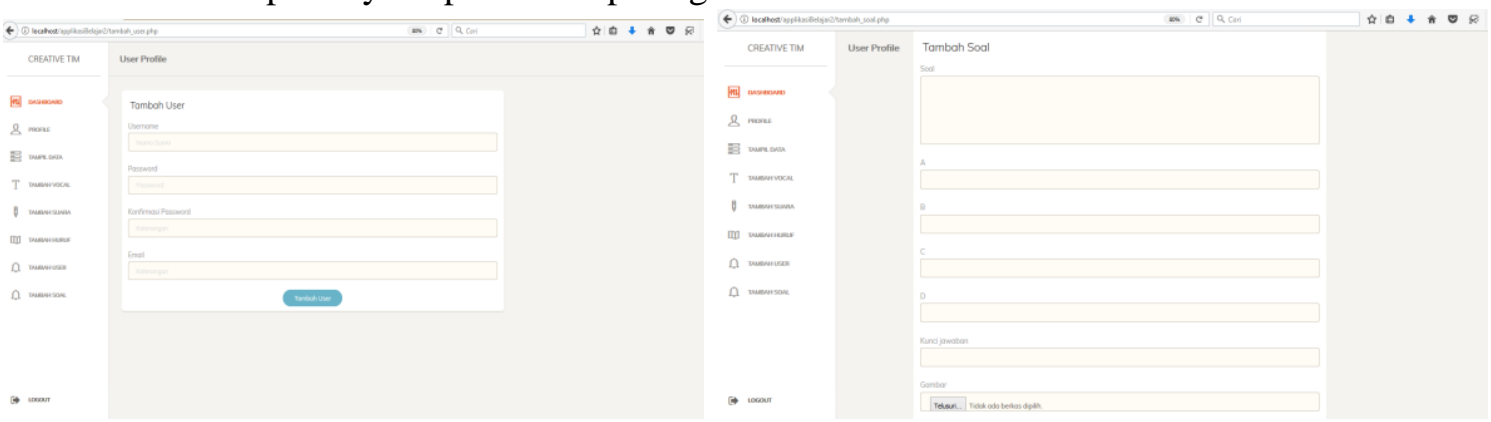

Gambar 13. Tampilan Hal Tambah Users

Gambar 14. Tampilan Hal Tambah Soal

7. Pada tampilan latihan, siswa dapat mengerjakan latihan siswa harus login terlebih dahulu. Setelah siswa menjawab akan dapat melihat hasil dari apa yang sudah dikerjakan.

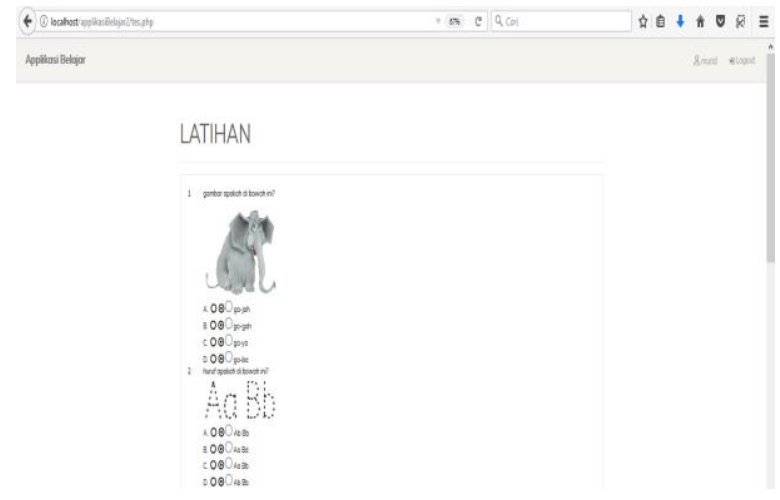

Gambar 19. Tampilan Halaman soal atau Latihan

\section{PENUTUP}

\subsection{Kesimpulan}

Mengacu pada rumusan masalah yang terdapat pada Bab 1 dan dilanjutkan dengan pembahasan pada Bab 4 maka dapat ditarik beberapa kesimpulan diantaranya :

1. Aplikasi pembelajaran membaca cepat dengan metode SB3 berbasis web mobile di TK Ibnu Sina Batam dirancang dengan menggunakan model

Data Flow diagram dan menggunakan bahasa pemprograman $P H P$ dan $M y S Q L$ sebagai database.

2. Pembelajaran Modul Satu Bulan Bisa Baca diterapkan dengan diaplikasikan ke dalam web mobile sebagai system aplikasi pembelajaran pada anak usia dini di TK Ibnu Sina Batam.

3 Hasil kuesioner dari 35 orang siswa ada $29 \%$ siswa tertarik untuk belajar dengan menggunakan system aplikasi pembelajaran membaca cepat

\subsection{Saran} dengan metode Satu Bulan Bisa Baca (SB3)

Adapun saran yang bertujuan untuk pengembangan applikasi ini agar lebih baik adalah:

1 Untuk Pengembangan aplikasi pembelajaran ini diharapkan pada soal latihan siswadapat disertai dengan suara

2 Menambahkan tabel nilai keseluruhan untuk siswa yang telah mengerjakan soal latihan 


\section{DAFTAR PUSTAKA}

Edi, D \&Betshani, S. (2009).Analisis Data dengan Menggunakan ERD dan Model Konseptual Data Warehouse, Jurnal InformatikaVol.5(1)

Faroki, A. \&Maula, B.(2014). Aplikasi Multimedia InteraktifPembelajaran Membaca, Menulis, Berhitung (calistung). Fakultas SainsdanTeknologi Vol.5 (2), ISSN: 19798911

Iswandy, E. (2015). Sistem Penunjang Keputusan .Jurnal TEKNOIF, Vol. 3(2), ISSN: 2338-2724

Lutviani, R.M. \& Noor, M. (2016).Aplikasi Pintar Membaca Huruf Hijaiyyah PadaAnakUsia Dini Berbasis Android. Jurnal Sains \& Informatika. Vol.2(2),

ISSN: $2460=173 \mathrm{X}$

Veza, O. (2017). Decision Support System (Dss) Dalam Prosedur Pengolahan Data Prakualifikasi Tender Pada Dinas Prasarana Jalan, Tata Ruang Dan Permukiman Propinsi Kepulauan Riau. Jurnal Teknik Ibnu Sina JT-IBSI, 2(1).

Maesaroh, S. \& Malkiah, N. (2015). Media Pembelajaran Interaktif Bahasa Inggris Pengenalan Huruf \& Membaca Berbasis Multimedia untuk SekolahDasar, Jurnal Sisfotek Global.Vo.5(1), ISSN: 2088-1762

Maimuna,M (2009). Media Pembelajaran Membaca dan Menulis Huruf Abjad, Jurnal TEKNOIF, Vol. 3(2),ISSN: 2321-2656

Putri, N.E. \&Azpar, S.(2013). Sistem Informasi Anak Usia Dini (PAUD) Terpadu Amalia Syukra Padang. Jurnal Edik Informatika

RahmaAnggraini, Vivi (2015) Kurikulum Tingkat SatuanPendidikan Taman Kanak-kanak Ibnu SinaBatam

Setyabudhi, A. L. (2017). PERANCANGAN SISTEM KERJA KOMPOR EKONOMIS DENGAN BAHAN BAKAR OLI BEKAS. Jurnal Teknik Ibnu Sina JT-IBSI, 2(1).

Sugiarso, Brave A., dkk.(2016). Rancang Bangun Aplikasi Pembelajaran Untuk Anak Umur 6-

9 Tahun Berbasis Android. E-Journal Teknik Informatika.Vol.7(1), ISSN: 2301-8364

Sulinda wati dan Fathoni, M. (2010).Pengantar Analisa PerancanganSistem. Jurnal Saintikom. Vol.9(2),

Sukarno, T (2007) Media Pembelajaran Interaktif Pengenalan Huruf \& Membaca Berbasis Multimedia, Padang. Jurnal Edik Informatika

Sutabri, T.(2012). Analisis Sistem Informasi. Syukra Padang STMIK Indonesia Padang.Jurnal Edik Informatika.

Veza, O. (2016). Simulasi Pengendalian Persedian Gas Menggunakan Metode Monte Carlo Dan Pola Lcm (Studi Kasus Di PT PKM Group Cabang Batam). Jurnal Teknik Ibnu Sina JTIBSI, 1(01).

Taufiq, R. (2013).Sistem Informasi Manajemen.JurnalEdik Informatika

Toha, M. (2012).Satu Bulan Bisa Baca.Sumatera Selatan: Era Adicitra Intermedia

Veza, O. (2017). Perancangan Sistem Informasi Inventory Data Barang Pada Pt. Andalas Berlian Motors (Studi Kasus: PT Andalas Berlian Motors Bukit Tinggi). Jurnal Teknik Ibnu Sina JT-IBSI, 2(2). 